J. Clin. Chem. Clin. Biochem.

Vol. 16, 1978, pp. 153-163

\title{
Intestinale Kohlenhydratabsorption - Koordination von Morphologie und Biochemie
}

\author{
Von R. Böhmer
}

Department für Klinische Chemie des Zentrums für Interdisziplinäre Medizinische Einheiten der Universität Ulm

(Eingegangen am 15. Februar/5. August 1977)

Zusammenfassung: Nach einer kurzen Darstellung der Morphologie der Dünndarmschleimhaut werden die physiologischen Vorgänge der Kohlenhydratdigestion und -absorption diskutiert. Während Stärke durch Amylase im Lumen des Duodenums hydrolytisch gespalten wird, findet die Disaccharidhydrolyse nicht im Darmlumen, sondern an der Bürstensaummembran der Dünndarmepithelzelle statt. Die freigesetzten Monosaccharide werden - zumindest teilweise - mittels eines spezifischen Transportsystems aktiv absorbiert. Dieser Mechanismus unterscheidet sich von denjenigen, die für den aktiven Transport primärer, d. h. nicht aus Oligosacchariden entstandener Monosaccharide verantwortlich sind. Die Ausschleusung der Monosaccharide aus der Dünndarmepithelzelle in den Extrazellularraum erfolgt durch erleichterte Diffusion (,facilitated diffusion“). Für den Übertritt in das Blutgefäßsystem wird eine Passage durch „gefensterte“ Kapillaren diskutiert.

\section{Intestinal carbohydrate absorption - correlation between morphology and biochemistry}

Summary: After a short description of the morphology of the small intestinal mucosa the physiological processes of carbohydrate digestion and absorption are discussed. While starch is hydrolyzed by amylase in the lumen of the duodenum, the disaccharide hydrolysis does not take place in the intestinal lumen, but at the brush border membrane of the enterocyte. The liberated monosaccharides are - at least in part - absorbed by a specific active transport system. This mechanism is different from those which are responsible for the active transport of primary monosaccharides, i.e. monosaccharides which do not result from oligosaccharide hydrolysis. The exit process for monosaccharides out of the enterocyte into the extracellular space occurs by "facilitated diffusion". Passage through "fenestrated" capillaries is discussed as a possible mechanism for the entry of monosaccharides into the blood vessel system.

\section{Einführung}

In der westlichen Welt bestehen die mit der normalen Kost aufgenommenen Köhlenhydrate (durchschnittlich $300 \mathrm{~g}$ pro Tag (1)) etwa zu $60 \%$ aus Stärke, zu $30 \%$ aus Saccharose und $\mathrm{zu} 10 \%$ aus Lactose $(2,3)$. Primäre Monosaccharide spielen mengenmäßig in der Nahrung keine Rolle (4). Stärke ist ein Polysaccharid, welches aus Glucosemolekülen aufgebăut ist, die mit $\alpha-1,4$-glykosidischen Bindungen aneinandergekoppelt sind. Das analoge $\beta$-1,4-Polysaccharid der Glucose, die Cellulose, kann im menschlichen Darm nicht gespalten werden. Nur ein kleiner Teil der Stärke kommt in unverzweigter Kettenform vor, während der größere Teil als verzweigtes Molekül (Amylopectin-Typ) vorliegt. Hierbei bestehen etwa $5 \%$ der Glucose-Glucose-Bindungen aus $\alpha-1,6-$ Bindungen, von denen erneut unverzweigte Seitenketten mit $\alpha-1,4-B i n d u n g e n$ ausgehen. Saccharose ( $\alpha$-Glucopyranosido- $\beta$-fructofuranosid) ist ein aus Glucose und Fructose bestehendes Disaccharid, während Lactose sich aus je einem Molekül Glucose und Galaktose zusammensetzt (4- $\beta$-Galäktosido-glucose).
Bevor die digestiv-absorptive Funktion des Dünndarmepithels erläutert wird, sollen zunächst die wesentlichen Strukturmerkmale der Mucosa dargestellt werden.

\section{Morphologie der Dünndarmmucoșa}

Die Funktionseinheit des Dünndarmes besteht aus Darmzotte (Villus) und Darmkrypten. Die Villushöhe beträgt im Rattenjejunum in Höhe des Treitzschen Bandes etwa $700 \mu \mathrm{m}$ und nimmt in distaler Richtung ab bis auf etwa $300 \mu \mathrm{m}$ im unteren Deum. Die Tiefe der Krypten bleibt mit etwa $200 \mu \mathrm{m}$ im gesamten Verlauf des Darmes annähernd konstänt (5). Im Jejunum der Ratte wird die Oberfläche eines Villus von etwa 10000 Epithelzellen gebildet (6), die jeweils eine Oberfläche von etwa $15 \mu \mathrm{m}^{2}$ aufweisen (7-9). Die Abbildung 1 zeigt eine Aufsicht auf die Jejunumschleimhaut der Ratte mit den in der Seitenansicht trapezförmigen und im Querschnitt ovalen Villi. Die Villi sind mit ihrem größten Querdurchmesser senkrecht zur Längsrichtung des Darmes und damit auch senkrecht zur Strömungsrichtung des Darminhaltes aus- 


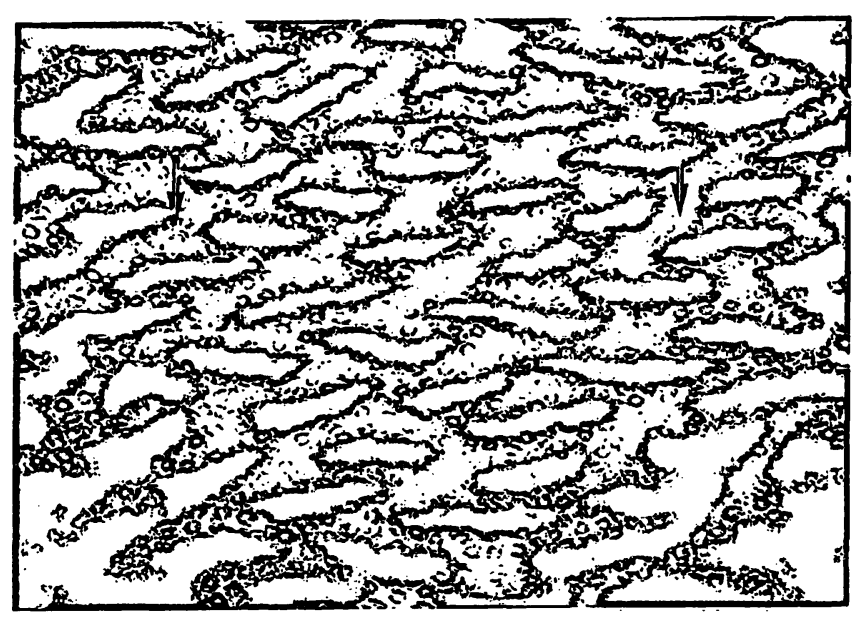

Abb. 1. Aufsicht auf die Jejunumschleimhaut, im durchscheinenden Licht photographiert (Ratte, $\times 25$ ).

Die dunklen Bezirke entsprechen den in der Aufsicht langgestreckt aussehenden Darmzotten; die die Zotten umgebenden Krypten erscheinen als kleine Kreise. Die Pfeile geben die Strömungsrichtung des Darminhaltes an.

gerichtet. $\mathrm{Zu}$ jedem Villus gehören mehrere Krypten (Abb. 2), deren Zahl von etwa 27 im oberen Dünndarm auf etwa 12 pro Villus im distalen lleum abnimmt (5, 10). Im höheren Lebensalter nimmt die Zahl der Krypten pro Villus zu, die Anzahl der Villi bleibt konstant (11). Die Mucosaepithelzellen, auch Enterocyten genannt, entstehen an der Basis der Krypte. Die Zellproduktionsrate pro Krypte ist in allen Dünndarmabschnitten annähernd konstant und beträgt etwa 36 Zellen/Krypte/ Stunde (5). Die Zellen wandern innerhalb 24 Stunden zur Basis der Zotte und gelangen nach einigen Tagen zur Zottenspitze, von der sie in das Darmlumen abge-

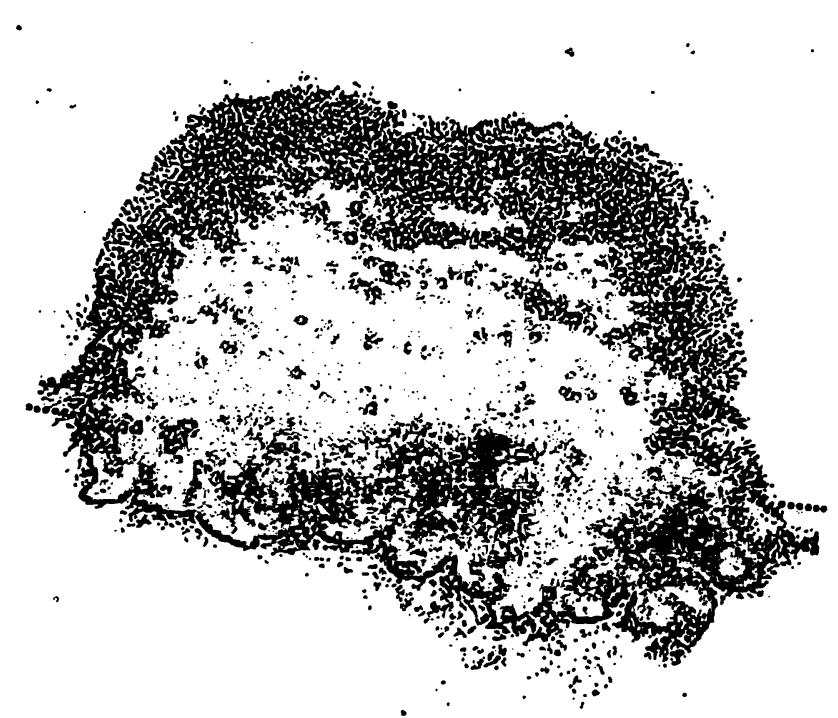

Abb. 2. Seitliche Ansicht einer Krypt-Villus-Einheit (Ratte, $x$ 40). An die basal gelegenen Krypten schließt sich in Richtung auf das Darmlumen die dazugehörige Zotte an. Die gepunktete Linie markiert die Krypt-Villus-Grenze. stoßen werden. Unter physiologischen Bedingungen entspricht die Zahl der neugebildeten Zellen der Zahl der in das Darmlumen sequestrierten Zellen. Die Wanderungszeit von der Basis zur Spitze der Zotte ist speciesunterschiedlich. Sie beträgt im oberen Dünndarm der Ratte etwa 32 bis 48 Stunden $(12,13)$, im menschlichen Duodenum und Jejunum etwa vier bis sechs Tage (14, 15). $\mathrm{Da}$, wie erwähnt, die Zottenhöhe nach distal abnimmt, die Zellregenerationsrate jedoch in allen Darmabschnitten gleich ist, ergibt sich eine abnehmende Lebensdauer der Enterocyten in Richtung auf das Ileum. Bei der Ratte beträgt die Zellwanderungșzeit im Ileum nur noch 17 Stunden (16). Die Angaben für die Abstoßungsund Regenerationsrate im menschlichen Dünndarm schwanken zwischen 20 bis $50 \times 10^{6}(17)$ und $170 \times$ $10^{6}$ Zellen pro Minute (18). Im gesamten Magen-DarmTrakt des Menschen werden etwa 250 bis $300 \mathrm{~g}$ Darmzellen täglich abgeschilfert $(19,20)$. Diese Zellen werden im Darmlumen verdaut, ihre Endprodukte werden zum größten Teil wieder absorbiert.

Der Aufbau der Dünndarmepithelschicht ist in den Abbildungen 3 und 4 dargestellt. Der Interzellularraum zwischen zwei Enterocyten wird durch die lateralen Zellmembranen der benachbarten Enterocyten sowie lumenwärts durch die ,tight junction“ und serosawärts durch eine gemeinsame Basalmembran begrenzt, die den basalen Zellmembranen der einzelnen Enterocyten anliegt. Serosawärts schließt șich an die Basalmembran die Lamina propria an. Die Funktion der „tight junctions“, die im Bereich des Schlußleistennetzes (s. u.) durch Fusion der aneinandergrenzenden äußeren Schichten zweier benachbarter Plasmamembranen entstehen, ist noch nicht abschließend geklärt. Der-Weg durch die „tight junctions“ stellt die Hauptroute für den transmuralen Natriumtransport von der Serosa- zur Mucosaseite dar $(21,22)$. An den lateralen Membranen der

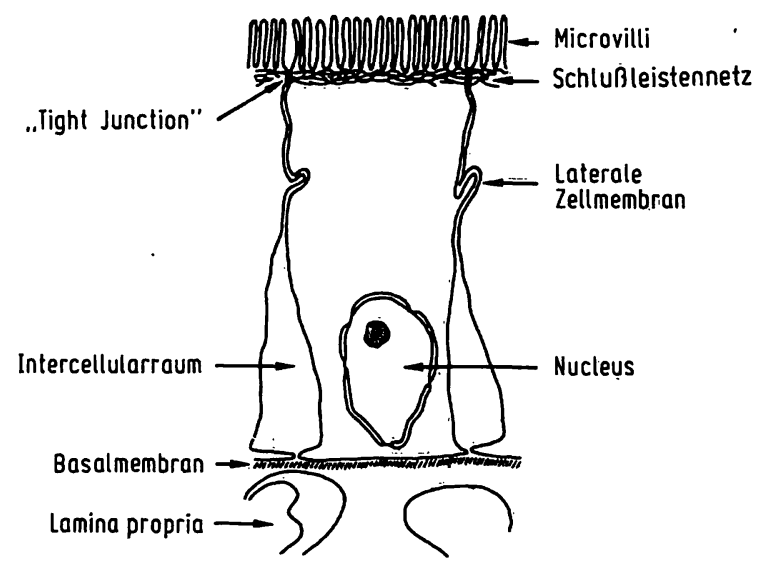

Abb. 3. Aufbau des Dünndarmepithels (schematisch). Die Mikrovilli bilden an der Lumenseite der Dünndarmepithelzelle den Bürstensaum, an den sich in Richtung . auf das Zellinnere das Schlußleistennetz anschließt. Der Interzellularraum zwischen den Epithelzellen wird von den lateralen Zellmembranen, der "tight junction" und der gemeinsamen Basalmembrän begrenżt. (modifiziert nach 1.c. (27)) 


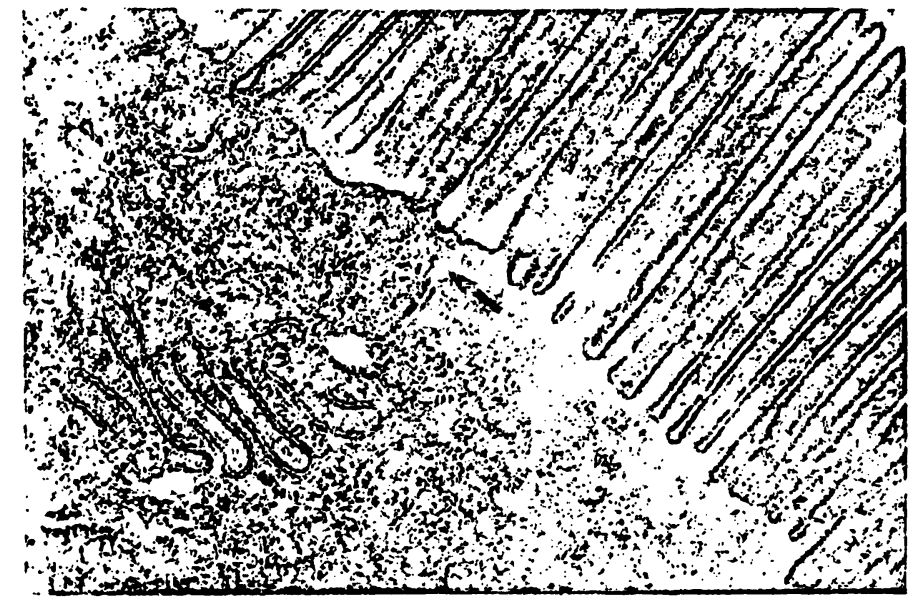

Abb. 4. Elektronenmikroskopisches Bild des apikalen Poles zweier aneinandergrenzender Enterocyten (Ratte, $\times 31.250)$.

Die in Längsrichtung verlaufenden Filamente der Mikrovilli gehen in das Schlußleistennetz über (siehe auch Abbildung 5). Das serpentinenartige Gebilde stellt den Interzellularraum dar, der am apikalen Zellpol von einer "tight junction" (Pfeil) begrenzt wird. Die schwarzen knopfartigen Figuren sind Desmosomen, die über cytoplasmatische Filamente mit dem Zellinnern in Verbindung stehen.

Epithelzellen befinden sich sogenannte Desmosomen, die über cytoplasmatische Filamente mit dem Zellinneren in Verbindung stehen. Uber ihre Funktion ist noch nichts Genaues bekannt.

Von Granger \& Baker (8) wurden erstmals fingerförmige Ausstülpungen der luminalen Zelloberfläche der Villuszelle beschrieben, die als Mikrovilli bezeichnet werden. Sie bilden in ihrer Gesamtheit den Bürstensaum der Mucosa. Die Mikrovilli haben eine Länge von 0,75 bis $1,7 \mu \mathrm{m}(7,23-25)$ und einen Durchmesser von etwa 0,1 bis $0,2 \mu \mathrm{m}(7,26,27)$. Der Raum zwischen zwei Mikrovilli hat eine Weite von 0,01 bis $0,05 \mu \mathrm{m}(26,28)$. Die Literaturangaben über die Anżahl der Mikrovilli pro Epithelzelle sind unterschiedlich. Für das menschliche Jejunum werden Zahlen zwischen 1700 (29) und 6500 (26) genannt, bei der Ratte schwanken die Angaben zwischen 950 und 3000 Mikrovilli pro Enterocyt (7-9). Durch die Mikrovilli wird die Oberfläche der Epithelzelle um etwa das 15 - bis 40 -fache vergrößert $(26,29,30)$.

Die Oberfläche der Mikrovilli wird von einer dreischichtigen Lipoproteinmembran gebildet, die in ihrer Gesamtheit als Bürstensaummembran bezeichnet wird. Diese wird lumenwärts von der beim Menschen etwa 0,1 und $0,5 \mu \mathrm{m}(27,31)$ dicken Glycocalyx, auch ,fuzzy coat" oder ,enteric surface coat" genannt, überzogen. Die Glycocalyx besteht nicht, wie zunächst àngenommen, aus adsorbiertem Schleim, sondern scheint im Golgiapparat der Zelle synthetisiert und von dort an die luminale Seite der Mikrovilli transportiert zu werden $(31,32)$. Sie ist ein integraler Bestandteil der Bürstensaummembran (33). Ihre Funktion ist noch nicht endgültig erklärt. Sie scheint jedoch einen Schutz der Zelle gegen cytotoxische
Substanzen (33) und gegen die Einwirkung luminaler Verdauungsenzyme auf die Bürstensaummembran (34) darzustellen.

In den Mikrovilli sind sowohl parallel als auch senkrecht zu ihrer Längsachse verlaufende Strukturen, sogenannte Filamente, dargestellt worden. Diese dienen der Strukturerhaltung der Mikrovilli und haben darüber hinaus wahrscheinlich eine dynamische Funktion (aktive Kontraktion der Mikrovilli?; (35)).

Die strukturelle Einheit von Bürstensaum und Zellinnerem wird durch das „terminal web“ oder Schlußleistennetz hergestellt, welches über die Filamente der Mikrovilli mit der Bürstensaummembran verbunden ist (Abb. $3-5)$.

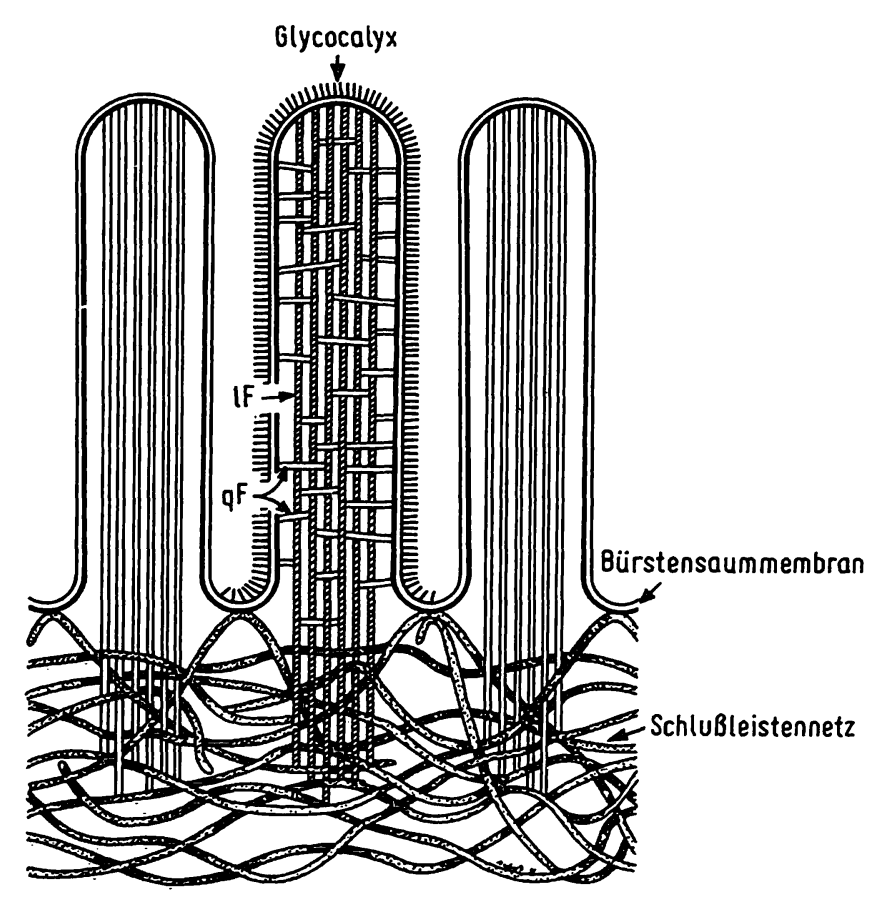

Abb. 5. Schematische Darstellung der Mikrovilli $\mathrm{qF}=$ quer verlaufende Filamente IF = längs verlaufende Filamente, die im Schlußleistennetz "verankert" sind.

(modifiziert nach l.c. (35))

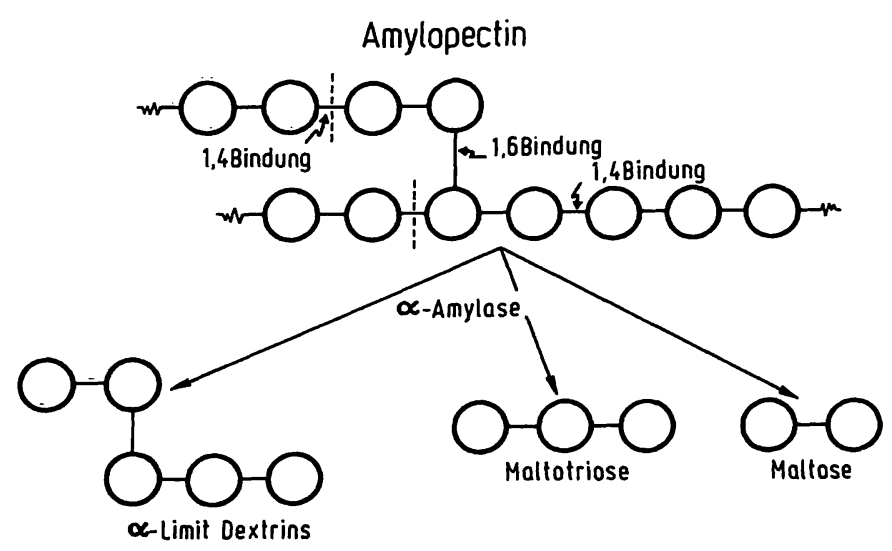

Abb. 6. Spaltung eines verzweigten Stärkemoleküls (Amylopectin-Typ) durch $\alpha$-Amylase.

Die Kreise symbolisieren Glucosemoleküle.

(modifiziert nach l.c. (2)) 


\section{Intraluminale Digestion der Stärke}

Die mit der Nahrung aufgenommene Stärke wird durch Speichel- und Pankreasamylase hydrolytisch gespalten (Abb. 6). Da Amylase ${ }^{1}$ ) nur mit den inneren 1,4-Bindungen des Stärkemoleküls reagiert, die endständigen 1,4Bindungen sowie die 1,6-Bindungen und die diesen unmittelbar benachbarten 1,4-Bindungen des Amylopectins jedoch nicht spalten kann, entstehen bei der Stärkedigestion keine Monosaccharide, sondern Disaccharide (Maltose), Trisaccharide (Maltotriose) und die sogenannten , $\alpha$-limit-dextrins“. Diese bestehen aus fünf oder mehr (im Durchschnitt acht) Glucosemolekülen mit einer oder mehreren 1,6-Bindungen. Die Stärkedigestion geschieht innerhalb weniger Minuten im Lumen des Duodenum (2).

\section{Vorstellungen zur Disacchariddigestion}

Die durch intraluminale Stärkedigestion entstandenen Spaltprodukte (Oligosaccharide) werden ebenso wie die mit der Nahrung unmittelbar zugeführten Disaccharide im Darmlumen nicht nennenswert gespalten, vielmehr findet die weitere Digestion in Monosaccharide in der Bürstensaummembran der Enterocyten statt $(2,36,37)$. Oda und Seki $(38,39)$, Johnson (40) und Nishi et al. (41) fanden elektronenmikroskopisch auf der äußeren Membranoberfläche von Mikrovilli kugelförmige Gebilde (,knobs“) von 5-6 nm Durchmesser, die als Träger von Disaccharidasenaktivitäten betrachtet wurden $(38,40)$. Diese Hypothese blieb nicht unwidersprochen, denn kurzfristige Papainbehandlung der Bürstensäume führte zu einer Solubilisation und einer Freisetzung von Disaccharidasen, jedoch nicht zu einem Verlust der „knobs“. Daraus wurde gefolgert, daß die „knobs" nicht als „Disaccharidasenpakete" angesehen werden können (42). Es gibt Hinweise darauf, daß auch in der Glycocalyx Disaccharidasenaktivität vorhanden ist (43).

Kürzlich wiesen Maroux et al. (44) durch Behandlung von Bürstensäumen mit dem Detergens Triton X 100 Peptidasen in amphipathischer Form nach, die sich von den durch Papain freigesetzten unterschieden. Dieser Befund wurde dadurch erklärt, daß die Bürstensaumhydrolasen aus einem hydrophilen ,Funktionsteil“ und einem sehr viel kleineren hydrophoben „Verankerungsteil" bestehen. Triton X 100 löst das gesamte Molekül aus seiner Verankerung in der Bürstensaummembran heraus, während Papain nur den in das Darmlumen hineinragenden, enzymatisch aktiven Funktionsteil abspaltet. Diese Beobachtungen sprechen dafür, daß die intestinalen Hydrolasen zu den oberflächlichen Strukturbestandteilen der Bürstensaummembran gehören (45). Von den Autoren wurde diskutiert, ob der „Verankerungsteil" neben der Aufgabe, das Molekül in der Bürstensaummembran zu fixieren, auch eine Rolle beim Transport der bei der Hydrolyse entstehenden Spaltprodukte (Glucose oder Aminosäuren) spielt (46).

\footnotetext{
1) 1,4- $\alpha$-D-Glucan-Glucanohydrolase EC 3.2.1.1
}

Ugolev (47) wies eine Adsorption von Pankreasamylase an die intestinale Mucosaoberfläche nach. Diese adsorbierte Amylase ist in der Lage, gelöste (nicht kolloidale) Stärke zu hydrolysieren. Wahrscheinlich spielen die adsorbierten Pankreasenzyme nur eine untergeordnete physiologische Rolle in Anbetracht der hohen intraluminalen Pankreasenzymaktivitäten $(48,49)$. Daneben nahm Ugolev (50) an, daß auch bei der Disacchariddigestion neben primär zellständigen, in der Bürstensaummembran lokalisierten Disaccharidasen adsorbierte Hydrolasen von Bedeutung sind. Für diese Kooperation von ortsständigen und adsorbierten Hydrolasen führte Ugolev den Begriff der „Membrandigestion" ein (50). Dạs menschliche Pankreas enthält Disaccharidasen (51), und beim Menschen wurde im Duodenalinhalt nach Pankreasstimulation ein Anstieg der Disaccharidasenaktivitäten nachgewiesen (52). Diese Aktivitäten sind jedoch so gering, daß sie für die Disacchariddigestion praktisch keine Rolle spielen (52). Die Disaccharidasen des Dünndarmes sind demnach nicht adsorbiert, sondern sie befinden sich ortsständig in der Bürstensaummembran $(45,53-55)$.

Die Disaccharidasen sind nicht gleichmäßig über den gesamten Bürstensaum verteilt. Die Aktivitäten sind an der Basis der Zotte gering, nehmen in Richtung auf die Spitze des Villus zu und sind an der Spitze selbst wieder vermindert, wie an Kryostatschnitten nachgewiesen wurde $(56,57)$. Da die Halbwertszeit von Disaccharidasen nur einige Stunden beträgt $(58,59)$, muß die Bürstensaummembran des Enterocyten fortlaufend mit „Nachschub“ an Disaccharidasen versorgt werden. Der isolierte Bürstensaum kann kein Protein synthetisieren (34). Eine Synthese von Saccharase und Maltase ${ }^{2}$ ) in der reifen Mucosazelle wurde während der Zellmigration von der Krypte zur Zottenspitze nachgewiesen (59). Der Kontrollmechanismus hierfür liegt in der Mucosazelle selbst und ist unabhängig von der Zellneubildung in der Krypte (59). In der Abbildung 7 sind die Disaccharidasenaktivitäten sowie die DNA- und Proteinsynthese der Enterocyten in Relation zur Lokalisation der Zelle auf der Zotte dargestellt.

Ein intrazellulärer, Actinomycin-D-hemmbarer Transportmechanismus für Disaccharidasen von ihrer Synthesestätte zur Bürstensaummembran wurde von Grand, Chong \& Isselbacher beschrieben (60). Einzelheiten über diesen Transport sind jedoch noch nicht hinreichend bekannt. Die Transportzeit der Disaccharidasen vom Bildungsort, den Mikrosomen, bis zur Bürstensaummembran beträgt etwa 6-10 Stunden (59).

\section{Klassifikation der menschlichen Disaccharidasen}

Disaccharidasen sind hydrolytische Enzyme, die entsprechend den von ihnen gespaltenen Bindungen in $\alpha$-Glucosidasen, $\beta$-Galaktosidasen und $\beta$-Glucosidase

\footnotetext{
$\left.{ }^{2}\right)$ Bezüglich der Nomenklatur wird auf den folgenden Abschnitt verwiesen.
} 


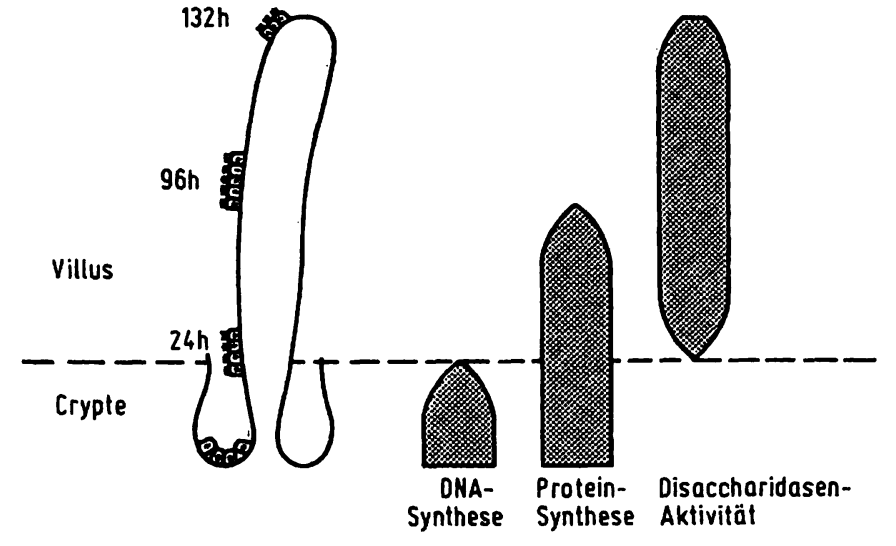

Abb. 7. Korrelation von Lage und Funktion der Enterocyten einer Krypt-Villus-Einheit.

Linke Bildhälfte: Die Enterocyten werden durch mitotische Teilung in den Krypten gebildet, wandern innerhalb von etwa 24 Stunden zur Zottenbasis und gelangen (beim Menschen) nach 4-6 Tagen zur Zottenspitze, von der sie in das Darmlumen abgestoßen werden.

Rechte Bildhälfte: Die mit Raster versehenen Flächen zeigen die Lokalisation (entsprechend der Lage der Flächen) und das Ausmaß (entsprechend der Breite der Flächen) der DNA- und Proteinsynthese sowie der Disaccharidasenaktivität. Die DNA-Synthese ist mit Erreichen der Zottenbasis abgeschlossen, während eine Proteinsynthese auch im reifen Enterocyten stattfindet. Die Disaccharidasenaktivität beginnt an der Basis der Zotte, erreicht ein Maximum während der Zellwanderung in Richtung auf die Zottenspitze und nimmt kurz vor der Zellabstoßung wieder ab (modifiziert nach 1.c. (2)).

eingeteilt werden können (Tab. 1). Die Nomenklatur $\operatorname{der} \alpha$-Glucosidasen wird international noch nicht einheitlich gehandhabt. Entsprechend den Empfehlungen der IUPAC/IUB Enzyme Nomenclature (1972) sollen auch die $\alpha$-Glucosidasen nach der EC-Nomenklatur unterteilt werden. Um der Forderung nach rationeller Nomenklatur nachzukommen, dem Leser das Verständnis jedoch nicht zu erschweren, werden im folgenden
Text die bisher allgemein gebräuchlichen Enzymnamen verwendet, während in Tabelle 1 die entsprechenden empfohlenen und systematischen Namen einschließlich ihrer EC-Nummern zusätzlich aufgeführt werden.

Aufgrund des unterschiedlichen Verhaltens der Maltasen bei Hitzeinaktivierung führte Dahlqvist (61) ein Numerierungssystem ein und unterschied Maltase I a, Ib, II und III. Auricchio, Semenza \& Rubino (62) unterschieden nach Auftrennung der $\alpha$-Glucosidasen durch Sephadexchromatographie fünf Maltasen (Maltase 1-5), von denen Maltase 3 und 4 das Substrat Saccharose und Maltase 5 das Substrat Isomaltose spalten. Wegen der Verwirrung in der Nomenklatur aufgrund der verschiedenen Numerierungssysteme schlug Dahlqvist (63) vor, jegliche Numerierung aufzugeben und die $\alpha$-Glucosidasen, wie in Tabelle 1 dargestellt, einzuteilen. Dabei entsprechen Isomaltase der Maltase Ia, Saccharase der Maltase Ib und die hitzestabilen Maltasen den Maltasen II und III der alten Dahlqvist-Nomenklatur (61). Außer den „Maltasen“ kommen Trehalase und Glucoamylase im Bürstensaum vor, wobei die Trehalase nur eine geringe praktische Bedeutung hat, da ihr Substrat, die $\alpha, \alpha-$ Trehalose, nur in Insekten und Pilzen vorkommt. Glucoamylase spaltet (im Gegensatz zur Pankreasamylase) endständige Glucosemoleküle von $\alpha$-1,4-Glucosyl-Oligosaccharidketten $\mathrm{ab}(2)$. Saccharase und Isomaltase sind zwei funktionell unabhängige Enzyme (64), obwohl sie strukturell in einer Art Komplex aneinander gebunden sind (63). Für eine solche Verbindung zweier Enzyme wurde von Semenza (65) der Begriff „Hyphezym“ geprägt.

Saccharase hydrolysiert das Disaccharid Saccharose, als Endprodukte entstehen Glucose und Fructose. Isomaltase spaltet Isomaltose, ein $\alpha$-1,6-Glucosyldisaccharid, in zwei Moleküle Glucose. $\mathrm{Da}$ im Darm jedoch keine freie Isomaltose vorkommt, sondern die einzigen Substrate mit $\alpha-1,6-B i n d u n g e n$ (nach Spaltung des Amylo-

Tab. 1. Einteilung der menschlichen Disaccharidasen

\begin{tabular}{|c|c|c|c|c|c|}
\hline \multicolumn{2}{|c|}{ Einteilung nach 1.c. (63) } & $\begin{array}{l}\text { Einteilung } \\
\text { nach 1.c. (61) }\end{array}$ & Empfohlener Name & Systematischer Name & EC-Nummer \\
\hline \multicolumn{6}{|c|}{ I. $\alpha$-Glucosidasen } \\
\hline $\begin{array}{l}\text { a) } \\
\text { b) }\end{array}$ & $\begin{array}{l}\text { Isomaltase } \\
\text { Saccharase }\end{array}$ & $\begin{array}{l}\text { Maltase Ia } \\
\text { Maltase Ib }\end{array}$ & $\begin{array}{l}\text { Oligo-1,6-glucosidase } \\
\beta \text {-Fructofuranosidase }\end{array}$ & $\begin{array}{l}\text { Dextrin } 6-\alpha \text {-glucanohydrolase } \\
\beta-D \text {-Fructofuranosid } \\
\text { Fructohydrolase }\end{array}$ & $\begin{array}{l}3.2 .1 .10 \\
3.2 .1 .26\end{array}$ \\
\hline $\left.\begin{array}{l}\text { c) } \\
\text { d) }\end{array}\right\}$ & $\begin{array}{l}\text { hitzestabile } \\
\text { Maltasen }\end{array}$ & $\begin{array}{l}\text { Maltase II und } \\
\text { Maltase IIII }\end{array}$ & $\alpha-$-Glucosidasè & $\alpha-D$-Glucosid Glucohydrolase & 3.2 .1 .20 \\
\hline & $\begin{array}{l}\text { Glucoamylase } \\
\text { Trehalase }\end{array}$ & & $\begin{array}{l}\text { Exo-1,4- } \alpha \text {-glucosidase } \\
\alpha, \alpha \text {-Trehalase }\end{array}$ & $\begin{array}{l}\text { 1,4- } \alpha-D \text {-Glucan Glucohydrolase } \\
\alpha, \alpha \text {-Trehalose Glucohydrolase }\end{array}$ & $\begin{array}{l}3.2 .1 .3 \\
3.2 .1 .28\end{array}$ \\
\hline \multicolumn{6}{|c|}{ II. $\beta$-Galaktosidasen } \\
\hline $\begin{array}{l}\text { a) } I \\
\text { b) } s \\
\text { c) } h\end{array}$ & $\begin{array}{l}\text { Lactase } \\
\text { aure } \beta \text {-Galaktosidase } \\
\text { Letero } \beta \text {-Galaktosidäse }\end{array}$ & $\begin{array}{l}\text { (Bürstensaum) } \\
\text { (Lysosomẹen) } \\
\text { (Cytoplasma) }\end{array}$ & $\beta$-Galaktosidase & $\beta-D$-Galaktosid Galaktohydrolase & 3.2.1.23 \\
\hline III. $\beta-G$ & lucosidase & & $\begin{array}{l}\text { B-Glucosidase } \\
\text { Phloretịn-glucosidase }\end{array}$ & $\begin{array}{l}\beta \text {-D-Glucosid Glucohydrolase } \\
\text { Phlorizin Glucohydrolase }\end{array}$ & $\begin{array}{l}3.2 .1 .21 \\
3.2 .1 .62\end{array}$ \\
\hline
\end{tabular}


pectins durch Amylase) die $\alpha$-limit-dextrins sind, schlug Gray (2) die Bezeichnung "Sucrase- $\alpha$-Dextrinase" anstelle von Saccharase-Isomaltase vor. Diese Nomenklaturänderung hat sich bisher in der Literatur noch nicht durchgesetzt.

Conklin et al. (66) haben den Saccharase-IsomaltaseKomplex isoliert und in die aktiven Komponenten Saccharase und Isomaltase zerlegt. Die Verschiedenartigkeit der beiden Molekülkomponenten, die unabhängig voneinander mit ihren Substraten reagieren, konnte aufgrund einer unterschiedlichen Reaktion mit einem Saccharase-Isomaltase-Antikörper bestätigt werden. Saccharase und Isomal tase scheinen durch einen gemeinsamen genetischen Faktor kontrolliert zu werden, da niemals ein angeborener Mangel nur eines Enzyms vorkommt, sondern immer eine gleichzeitige Verminderung von Saccharase und Isomaltase $(67,68)$. Bei Patienten mit Saccharase-Isomal tasemangel postulierten Dubs et al. (68) aufgrund von Immunofluoreszenzuntersuchungen das Vorkommen eines enzymatisch inaktiven Enzymproteins in der Dünndarmmucosa. Daneben konnten diese Autoren in der Dünndarmmucosa des Kaninchens funktionell inaktive Saccharasevorstufen nachweisen (69). Aus ihren Ergebnissen schlossen sie, daß - zumindest beim Kaninchen - zwei Schritte bis zum Erscheinen des aktiven Enzyms notwendig sind: Bildung der inaktiven Vorstufe und Aktivierung zur funktionell wirksamen Saccharase. Dieser Hypothese stehen die Ergebnisse anderer Arbeitsgruppen entgegen, die beim Menschen mit Saccharase-Isomaltasemangel weder radioimmunologisch (70) noch mittels Gelelektrophorese (71) inaktive Enzymproteine nachweisen konnten.

Bei den $\beta$-Galaktosidasen unterscheidet man die im Bürstensaum liegende Lactase sowie intrazellulär die saure $\beta$-Galaktosidase (lysosomal) und die hetero- $\beta$ Galaktosidase (cytoplasmatisch) (72-74). Nur die Bürstensaumlactase spielt für die Lactosedigestion eine Rolle. Nach einer Hypothese von Gray und Mitarbeitern (75) könnte die cytoplasmatische hetero- $\beta$-Galaktosidase als Vorstufe der Bürstensaumlactase angesehen werden. Untersuchungen von Grand, Chong \& Isselbacher (60) deuten darauf hin, daß Disaccharidasen intrazellulär synthetisiert und mittels eines noch nicht näher identifizierten Mechanismus in den Bürstensaum transportiert werden, da isolierte Bürstensäume nicht in der Lage sind, Eiweiß zu synthetisieren (34).

Eine $\beta$-Glucosidase ist die Phloretin-glucosidase (Phlorrhizinhydrolase), deren Aktivität zu $75 \%$ eine spezifische $\beta$-Glucosidaseaktivität ist, während $25 \%$ der Aktivität. durch Lactase (unspezifischer Effekt) hervorgerufen werden (76).

\section{Hypothesen zur Monosaccharidabsorption}

Für den Transport einer Substanz durch eine Membran werden heute vor allem folgende Mechanismen diskutiert (77):
Physikalische Interaktionen $z$ wischen Substrat und Zellmembran

\section{Dabei erfolgt eine Diffusion}

1. durch Poren, abhängig vom Diffusionskoeffizienten innerhalb der Poren,

2. durch die Membran, abhängig von der Löslichkeit des Substrates innerhalb der Membran und vom Diffusionskoeffizienten in der Membran.

Diese Transportmechanismen sind konzentrationsabhängig, mit steigender Konzentration gelangt mehr Substrat in das Zellinnere.

\section{Chemische Interaktionen $z w$ ischen Substrat und Zellmembran}

Voraussetzung hierfür ist das Vorhandensein eines spezifischen Systems an der Zellmembran, mit dem das Substrat eine Bindung eingehen kann.

Hierbei kann es sich um folgende Transportarten handeln:

1. Energieunabhängiger Transport („,Facilitated diffusion"). Dieser erfolgt nur in Richtung eines Konzentrationsgradienten („Bergabtransport").

2. Energieabhängiger Transport („Aktiver Transport"). Dieser kann gegen einen Gradienten erfolgen. Die Energie wird bereitgestellt durch

a) Kopplung des Transportprozesses an die Spaltung energiereicher chemischer Verbindungen, z. B. ATP,

b) Kopplung des Transportprozesses an den Transport einer anderen Substanz entsprechend deren elektrochemischem Gradienten.

3. Synthesegekoppelter Transport, d. h. Substrattransport entsprechend einem elektrochemischen Gradienten, wobei dieser durch Kopplung mit der Synthese energiereicher Stoffwechselprodukte aufrechterhalten wird, die entweder gespeichert oder direkt für den Transport benötigt werden.

\section{Transport durch Vesiculation der Zellmembran (Pinocy tose)}

Über die Definition des Begriffes „Aktiver Transport“ konnte bisher noch keine Einigung erzielt werden. Nach Rosenberg (78) versteht man unter aktivem Transport einen Prozeß, der den Nettotransport einer Substanz von einem Ort niedriger zu einem Ort höherer Potentialdifferenz hervorruft. Kedem (79) schlug vor, als einziges Kriterium für aktiven Transport eine direkte Verbindung zwischen Substrattransport und Stoffwechselreaktionen heranzuziehen. Der Unterschied zwischen beiden Definitionen läßt sich am Beispiel der Glucoseabsorption veranschaulichen, die nach Rosenberg als aktiv bezeichnet werden muß, da sie entgegen einem elektrochemischen Gradienten stattfindet, während sie nach Kedem einen passiven Mechanismus darstellt, da sie nicht direkt mit Stoffwechselreaktionen verknüpft ist. Als ,,aktiv" werden nach Parsons alle diejenigen Transportsysteme bezeichnet, deren Funktion nicht durch außerhalb degs 
Systems vorhandene Kräfte (z. B. elektrochemischer Gradient) erklärt werden kann, sondern deren Funktion an das Vorhandensein eines im System liegenden „Motors" gebunden ist (77). Entsprechend dieser Definition ist der Monosaccharidtransport vom Darmlumen in die Mucosazelle ein aktiver Prozeß, der mittels eines sogenannten (hypothetischen) Carriers stattfindet. Prinzipiell sind zwei Arten von Carriern denkbar:

\section{Kettenförmig aneinandergereihte, unbewegliche Sub-} stratbindungsstellen (80),

2. bewegliche Carrier (81).

Im kettenförmig angelegten Transportsystem soll sich das Substratmolekül nacheinander an verschiedene Bindungsstellen anlagern, bis es an der Innenseite der Membran angelangt ist.

Das Prinzip des beweglichen Carriers (Abb. 8) besteht darin, daß er sich, an der äußeren Oberfläche der Zellmembran liegend, mit dem Substrat verbindet. Unter Drehung um $180^{\circ}$ bewegt sich der Carrier-Substrat-Komplex durch die Membran zur inneren Membranoberfläche, an der sich das Substrat vom Carrier löst. Danach bewegt sich der Carrier unter erneuter Drehung an die äußere Oberfläche zurück.

Bezüglich des Zuckertransportes stehen sich zwei Hypothesen über den Carriermechanismus gegenüber. Beide stimmen darin überein, daß der aktive Monosaccharidtransport natriumabhängig ist. Nach Ansicht von Csaky $(82,83)$ wird $\mathrm{Na}^{+}$nicht an den Zuckercarrier gebunden,

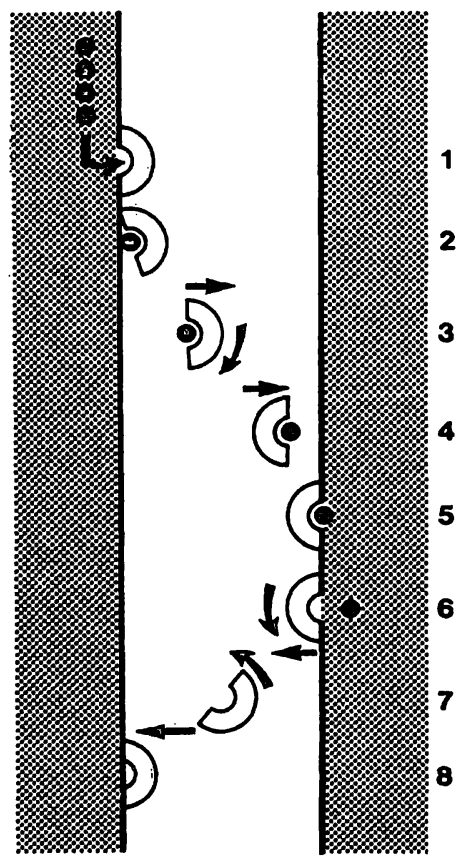

Abb. 8. Modell des beweglichen Carriers

Das Substrat $\bullet$ bildet mir dem an der Lumenseite liegenden Carrier (2) einen Komplex $\bullet$ ); dieser durchwandert unter Drehung um $180^{\circ}$ die Zellmembran, gibt an der dem Zellinneren zugewandten Seite der Zellmembran das Substrat $a b$ und kehrt unter erneuter Drehung an die Membranaußenseite zurück (modifiziert nach 1.c. (77)). sondern es wird zur intrazellulären Umwandlung von chemischer Energie in „Pumpenergie" benötigt, wobei ATPase eine wichtige Rolle spielen soll. Es sei eine kritische intrazelluläre $\mathrm{Na}^{+}$-Konzentration notwendig für das Funktionieren der „Zuckerpumpe“ (82). Diese von Csaky vertretene Hypothese wird als das Prinzip des „direkt coupling“ $z$ wischen intrazellulärem Natrium und Zuckertransport bezeichnet.

Der Hypothese des „,direct coupling“ steht das von Crane aufgestellte Modell des ,indirect coupling" gegenüber. Es besagt, daß das intrazelluläre $\mathrm{Na}^{+}$nicht unmittelbar am Monosaccharidtransport teilnimmt. Der energieverbrauchende Prozeß soll darin bestehen, daß Na${ }^{+}$ an der lateralen und basalen Zellmembran aktiv aus der Mucosazelle in den Interzellularraum heraustransportiert wird („Natriumpumpe“). Aufgrund eines $\mathrm{Na}^{+}$-Konzentrationsgradienten $\mathrm{zwischen} \mathrm{Intrazellularraum}$ und dem Medium an der Lumenseite des Enterocyten kommt es nach Bindung des $\mathrm{Na}^{+}$an einen Carrier zu einem passiven Einstrom von $\mathrm{Na}^{+}$durch die Bürstensaummembran in die Zelle. Dieser Vorgang des energieunabhängigen, jedoch carriervermittelten Transportes wird als „erleichterte Diffusion" (,facilitated diffusion") bezeichnet. Der Carrier hat neben der $\mathrm{Na}^{+}$-Bindungsstelle eine weitere Bindungsstelle für ein Monosaccharidmolekül, so daß das Monosaccharid „huckepack" mit dem (passiven) $\mathrm{Na}^{+}$-Transport in die Zelle gelangt. Die Bindung von $\mathrm{Na}^{+}$ an den Carrier an der Lumenseite der Zellmembran soll die Affinität des Zuckers zum Carrier steigern. Nach der Membranpassage des $\mathrm{Na}^{+}$-Zucker-Carrier-Komplexes löst sich $\mathrm{Na}^{+}$an der Innenseite der Membran vom Carrier ab, und stattdessen lagert sich $\mathrm{K}^{+}$an. Durch diese Bindung von $\mathrm{K}^{+}$wird die Affinität des Monosaccharids zum Carrier vermindert, so daß das Zuckermolekül intrazellulär freigesetzt wird. Der $\mathrm{K}^{+}$-Carrier-Komplex wandert entsprechend dem $\mathrm{K}^{+}$-Gradienten zurück zur Zellaußenseite, wo $\mathrm{K}^{+}$abgegeben und $\mathrm{Na}^{+}$angelagert wird, so daß der Cyclus von vorn beginnen kann (84). Die Abbildung 9 zeigt schematisch das Modell des ,,indirect coupling“. Eine kritische Gegenüberstellung der von den meisten Untersuchern akzeptierten ,,indirect coupling“-Hypothese mit der des "direct coupling" findet sich in einer Ubersichtsarbeit von Kimmicin (85).

Während bei in vitro-Untersuchungen eine $\mathrm{Na}^{+}$-Abhängigkeit des aktiven Glucosetransportsystems nachgewiesen wurde, sind die Angaben über den Einfluß des luminalen Natriumgehaltes auf die Zuckerabsorption in vivo widersprüchlich. Olsen \& Ingelfinger (86) fanden beim Menschen einen verminderten aktiven Glucosetransport bei $\mathrm{Na}^{+}$-freiem Perfusionsmedium. Demgegenüber stellten Saltzman et al. (87) sowie McMichael (1) keine Änderung der Glucoseabsorption bei Verwendung einer $\mathrm{Na}^{+}$. freien Perfusionslösung fest. Diese scheinbare $\mathrm{Na}^{+}-$Unabhängigkeit in vivo wird durch die Hypothese zu erklären versucht, daß $\mathrm{Na}^{+}$aus der Epithelzelle (durch die tight junctions?) in das Lumen diffundiert und somit an der Lumenseite der Bürstensaummembran ein $\mathrm{Na}^{+}$-haltiges 


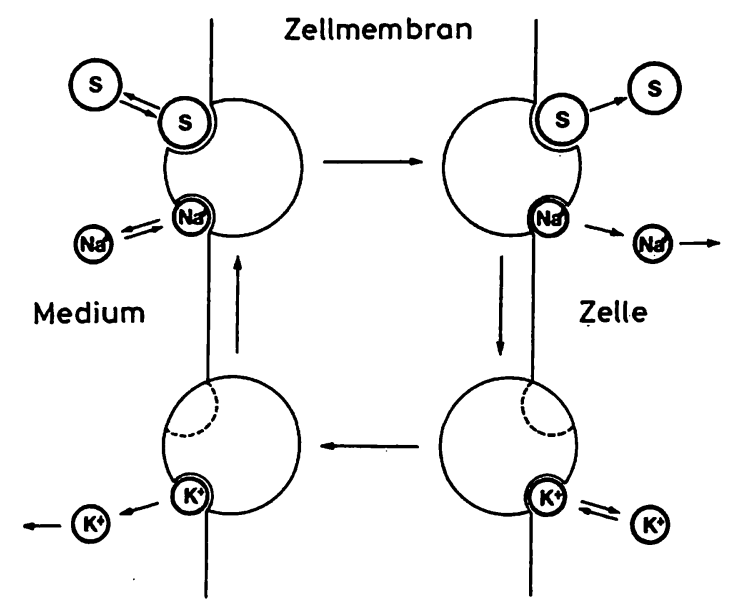

Abb. 9. Schematische Darstellung des "indirekt coupling"Modells für den aktiven Zuckertransport.

Der Carrier bindet an der Lumenseite der Zellmembran (links im Bild) $\mathrm{Na}^{+}$und Substrat (S) an zwei getrennten Bindungsstellen. Der $\mathrm{Na}^{+}$-Substrat-Carrier-Komplex durchwandert die Membran, gibt an der Innenseite der Membran $\mathrm{Na}^{+} \mathrm{ab}$ und lagert stattdessen $\mathrm{K}^{+}$an. Durch diesen Vorgang wird die Affinität des Carriers zum Substrat vermindert, und das Substrat wird in das Zellinnere freigesetzt. Entsprechend dem $\mathrm{K}^{+}$-Gradienten (hohes intrazelluläres $\mathrm{K}^{+}$) wandert der $\mathrm{K}^{+}$-Carrier-Komplex an die Membranaußenseite zurück. (nach l.c. (84))

„Mikroklima“ bildet, so daß trotz eines natriumfreien Perfusates der Glucosetransport in einem natriumhaltigen Milieu stattfindet (87). Untersuchungen von Murer \& Hopfer (88) zeigten, daß ein elektrisches Potential an der Bürstensaummembran (negativer Pol innerhalb der Zelle) ebenfalls eine wichtige Rolle beim $\mathrm{Na}^{+}$-gekoppelten aktiven Glucosetransport spielt.

Während man für Glucaloge, d. h. für Zucker vom $D$ Glucosetyp, zunächst ein gemeinsames einheitliches Transportsystem angenommen hatte, konnten in den letzten Jahren beim Hamster unterschiedliche $\mathrm{Na}^{+}$-abhängige Systeme nachgewiesen werden $(89,90)$. Das mit „Carrier 1" bezeichnete Transportsystem ist relativ unspezifisch, während der „Carrier 2" nur Glucose und Galaktose transportiert. Der relative Anteil des Carriers 2 an der Gesamtcarrierkapazität nimmt in Richtung auf das distale Ileum zu, ebenso wird sein Anteil mit zunehmendem Alter der Tiere größer (90). Neuere Untersuchungen an der Ratte sprechen ebenfalls für das Vorliegen multipler Zuckercarrier (91).

Keines der beiden genannten Carriersysteme ist mit dem Fructosetransportsystem identisch. Fructose, die beim Menschen $(92,93)$ und bei der Ratte (94) im Enterocyten nicht metabolisiert, sondern unverändert in das. Portalblut transportiert wird, wird mittels eines eigenen Carriersystems (95-97) absorbiert, welches die Fructose gegen einen Konzentrationsgradienten in die Dünndarmepithelzelle einschleust (97). Uber die $\mathrm{Na}^{+}$-Abhängigkeit dieses Transportsystems besteht noch Unklarheit. Gracey et al. (97) fanden eine verminderte Fructoseabsorption im $\mathrm{Na}^{+}$-freien Milieu, während andere Autoren einen $\mathrm{Na}^{+}$unabhängigen Mechanismus beschrieben $(95,96)$.
Interaktionen zwischen Disacchariddigestion und Monosaccharidabsorption

Nachdem der Nachweis geführt war, daß sowohl hydrolytische Enzyme (98) als auch Transportsysteme (99) an die Bürstensaummembran gebunden șind, wurden Untersuchungen durchgeführt, die neben der räumlichen Nachbarschaft auch eventuelle funktionelle Beziehungen zwischen Digestions- und Abșorptionsvorgängen aufklären sollten. Es scheint heute festżustehen, daß neben dem Prinzip des $\mathrm{Na}^{+}$-abhängigen Monosaccharidcarriers, auch Carrier A genannt, ein zwweiter Carriermechanismus besteht, der speziell die durch Disaccharidspaltung freigesetzten Monosaccharide transportiert (Carrier B). Dieser Transportprozeß ist nicht oder nur wenig $\mathrm{Na}^{+}$-abhängig und wurde für die Spaltprodukte von Saccharose, İsomaltose, Maltose und Trehalose nachgewiesen $(100,101)$. Der Funktionsmechanismus des Carriers B ist noch nicht geklärt. Es wird diskutiert, daß einige Hydrolasen in der Art in die Bürstensaummembran eingebaut sind, daß sie sich an der zum Darmlumen gerichteten Seite der Membran mit dem Disaccharid verbinden und an der zellinneren Seite einen Teil der Disaccharidspaltprodukte freisetzen (100). Diese Hypothese wird durch Untersuchungen von Storelli, Vögeli \& Semenża (102) gestützt, die nach Inkorporation eines Saccharase-Isomaltase-Komplexes in Lipidmembranen eine höhere Permeabilität für aus Saccharose freigesetzte Glucose und Fructose nachweisen konnten als für primär freie Glucose und Fructose. Membranen ohne Saccharase-Isomaltase-Komplexe waren praktisch nicht permeabel für Saccharose, Glucose und Fructose. Die Monosaccharidpermeation bei Anwesenheit des Saccharase-Isomaltase-Komplexes war $\mathrm{Na}^{+}$unabhängig. Für die bevorzugte Absorption der aus Disacchariden freigesetzten Monosaccharide gegenüber primär freien Monosacchariden wurde der Begriff des „,kinetischen Vorteils" (,kinetic advantage") eingeführt (53). Wegen der engen räumlichen und funktionellen Verknüpfung von Digestion und Absorption der Kohlenhydrate prägte Crane (103) den Begriff der ,digestivabsorptiven Oberfläche“ (,digestive-absorptive-surface“).

Untersuchungen am Menschen zeigten beim Gesunden keine Korrelation zwischen Disaccharidasenaktivität, gemessen an Biopsiestuickchen, und der Disacchariddigestion im Perfusionsexperiment $(3,104,105)$. Aus diesen Ergebnissen kann geschlossen werdēn, daß beim Gesunden nicht die Aktivitäten der Disaccharidasen, sondern andere Faktoren die Hydrolyse- und Absorptionsrate von Disacchariden bestimmen, z. B. der Membrantransport der freigesetzten Monosaccharide. Möglicherweise hemmen die lokal akkumulierten Disaccharidspaltprodukte die weitere Hydrolyse der Disaccharide (28). An der Ratte wiesen Dahlquist \& Thomson (106) ebenfalls nach, daß nicht die Hydrolyse der Saccharose, sondern die Absorption der Spaltprodukte geschwindigkeitsbestimmend ist. 
Transport der absorbierten Monosaccharide aus dem Enterocyten in die Blutbahn

Die durch die Bürstensaummembran in die Mucosazelle gelangten Monosaccharide können entweder intrazellulär metabolisiert werden und als Metaboliten in die Blutbahn gelangen oder unverändert in das Pfortadersystem abgegeben werden. In jedem Falle müssen die lateralen und/oder basalen Zellmembranen durchdrungen werden. Murer et al. (107) trennten die baso-lateralen Plasmamembranen der Mucosazelle des Rattendünndarms mittels trägerfreier Elektrophorese von der Bürstensaummembran $\mathrm{ab}$ und untersuchten in beiden Fraktionen getrennt die Glucosetransportmechanismen. Sie konnten den $\mathrm{Na}^{+}$-abhängigen ,Bergauf“-Transport an der Bürstensaummembran bestätigen und wiesen außerdem nach, daß der Austritt von Glucose aus der Zelle über die basolaterale Plasmamembran als $\mathrm{Na}^{+}$-unabhängiger ,Bergab“Transport erfolgt. Kimmich \& Randles (108) fanden an der isolierten Dünndarmzelle des Huhnes ebenfalls einen $\mathrm{Na}^{+}$-unabhängigen Ausschleusungsmechanismus für Monosaccharide im Sinne einer "facilitated diffusion“. Die Zuckeraufnahme über die laterale und basale Zellmembran des isolierten Mäuseenterocyten wurde von Bihler \& Cybulsky (14) untersucht, die eine ,facilitated diffusion" nachweisen konnten. Der Austritt von Monosacchariden aus dem Enterocyten wurde von diesen Autoren nicht geprüft. Die ,facilitated diffusion“ ist jedoch kein asymmetrischer Prozeß, sondern sie kann in beiden Richtungen entsprechend dem Konzentrationsgradienten ablaufen. Diese Tatsache und die berichteten Ergebnisse lassen den Schluß zu, daß der Monosaccharidtransport aus der Mucosazelle heraus ein carriervermittelter, energieunabhängiger Prozeß im Sinne einer ,facilitated diffusion" ist. Diese Annahme steht auch im Einklang mit den Ergebnissen von Bronk \& Ingham (109), die einen bidirektionalen, carriervermittelten Galaktosetransport am serosalen Pol der Mucosaepithelzelle des Rattendünndarms fanden. Dieser Mechanismus scheint im übrigen auch für den Transport anderer Monomere zu gelten. So fand Munck (110) am Rattendünndarm für Lysin ebenfalls einen durch eịe Sättigungskinetik ge= kennzeichneten Ausschleusungsprozeß.

Obwohl am isolierten Enterocyten (108) bzw. an isolierten Zellmembranen (107) der Transportmechanismus für Monosaccharide an der baso-lateralen Zellmembran nicht $\mathrm{Na}^{+}$-abhängig ist, konnten Boyd et al. beim Frosch an einem Dünndarmpräparat mit intaktem Blutgefäßsystem eine verminderte Erscheinungsrate von 3-O-Methylglucose in der Blutbahn beobachten, wenn das Blutgefäßsystem mit einer $\mathrm{Na}^{+}$-freien Lösung durchströmt wurde (111). Die Autoren führten diese in vivo gefundene $\mathrm{Na}^{+}$-Abhängigkeit des 3-O-Methylglucosetransportes von der Zelle in die Blutbahn darauf zurück, daß $\mathrm{Na}^{+}$den Extrazellularraum in der Mucosa vergrößerte. Dieser Vergrößerung entsprächen eine gesteigerte 3-OMethylglucoseclearance des Extrazellularraumes und somit ein verstärkter Monosaccharideinstrom in die Blutbahn. Derartige Beziehungen können mit in vitroTechniken am isolierten Enterocyten oder mit Messung der Substraterscheinungsrate im serosalen Inkubationsmedium nicht erfaßt werden.

Zusammenfassend kann als gesichert gelten, daß die Ausschleusung von Monosacchariden aus dem Enterocyten in den Extrazellularraum über die baso-laterale Zellmembran durch einen carriervermittelten, $\mathrm{Na}^{+}$-unabhängigen Diffusionsprozeß (,facilitated diffusion") erfolgt. Die Monosaccharidclearance des Extrazellularraumes scheint demgegenüber $\mathrm{Na}^{+}$-abhängig zu sein.

Als Mechanismus für die Aufnahme der Monosaccharide in das Blutgefäßsystem wird eine Einschleusung über „gefensterte " Kapillaren diskutiert. Im Katzendünndarm finden sich kapilläre Endothelfenster hauptsächlich an den Zottenspitzen und - in geringerer Zahl - in den Krypten (112). Im venösen Schenkel der Mikrozirkulation konnten mehr Fenster nachgewiesen werden als im arteriellen Schenkel. Mittels der gefensterten Kapillaren wird ein extravasaler Flüssigkeitskreislauf zwischen arteriellem und venösem Schenkel aufrechterhalten, der pro $100 \mathrm{~g}$ Jejunumgewebe etwa $0,4 \mathrm{ml}$ Flüssigkeit pro Minute umwälzt. Der Flüssigkeitsabstrom über die Lymphe beträgt demgegenüber mit etwa $0,05 \mathrm{ml} / \mathrm{min} /$ $100 \mathrm{~g}$ Gewebe etwa $10 \%$ dieses extravasalen Kreislaufes (112).

\section{Danksagung}

Herrn Dr. R. Ecknauer, Department für Klinische Chemie der Universität Ulm, danke ich für die freundliche Überlassung der Abbildungen 1 und 2.

\section{Literatur}

1. Mc Michael, H. B. (1975), Biochem. Soc. Trans. 3, 223-227.

2. Gray, G. M. (1975), N. Engl. J. Med. 292, 1225-1230.

3. Mc Michael, H. B. (1971), Proc. Nutr. Soc. 30, 248-254

4. Yudkin, J. (1967), Am. J. Clin. Nutr. 20, 108-115.

5. Clarke, R. M. (1970), J. Anat. (London) 107, 519-529.

6. Clarke, R. M.: persönliche Mitteilung.

7. Anderson, J. H. \& Taylor, A. B. (1973), J. Morphol. 141, 281-291.

8. Granger, B. \& Baker, R. F. (1950), Anat. Rec. 107, 423-436.

9. Palay, S. L. \& Karlin, L. J. (1969), J. Biophys. Biochem. Cytol. 5, 363-372.

10. Clarke, R. M. (1972), J. Anat. (London) 112, 27-33. 
11. Clarke, R. M. (1971), J. Anat. (London) 109, 352.

12. Koldovsky, O., Sunshine, P. \& Kretchmer, N. (1966), Nature 212, 1389-1390.

13. Leblond, C. P. \& Stevens, C. E. (1948), Anat. Rec. 100, 357-371.

14. MacDonald, W. C., Trier, J. S. \& Everett, N. B. (1964), Gastroenterology 46, 405-427.

15. Shorter, R. G., Moertel, C. G., Titus, J. L. \& Reitemeier, R. J. (1964), Am. J. Digest. Diseases 9, 760-763.

16. Altmann, G. G. \& Enesco, M. (1967), Am. J. Anat. 220, 319-336.

17. Croft, D. N. \& Cotton, P. B. (1973), Digestion 8, 144-160.

18. Crosby, W. H. (1961), Am. J. Dig. Dis. 6, 492-498.

19. Croft, D. N. (1970), Proc. Roy. Soc. Med. 63, 11-14.

20. Leblond, C. P. \& Walker, C. E. (1956), Physiol. Rev. 36, 225-276.

21. Clarkson, T. W. (1967), J. Gen. Physiol. 50, 695-727.

22. Frizzell, R. A. \& Schultz, S. G. (1972), J. Gen. Physiol. 59, 318-346.

23. Curran, R. C. \& Craemer, B. (1963), J. Pathol. Bacteriol. $86,1-8$.

24. Haubrich, W. S., Watson, J. H. L., O'Driscoll, W. \& Valentine, V. (1959), Henry Ford Hosp. Med. Bull. 7, 113-122.

25. Shearman, D. J. C., Girdwood, R. H., Williams, A. W. \& Delamore, I. W. (1962), Gut 3,16-25.

26. Marsh, M. N. \& Swift, J. A. (1969), Gut 10, 940-949.

27. Trier, J. S. (1968), In: Handbook of Physiology, Section 6 , Alimentary Canal. Vol. III, Intestinal Absorption. (Code, C. F., ed.) 1125-1175, American Physiological Society, Washington D.C.

28. Hamilton, J. D. \& Mc Michael, H. B. (1968), Lancet $I$, 154-157 (1968).

29. Brown, A. L. Jr. (1962), J. Cell Biol. 12, 623-627.

30. Zetterqvist, H. (1956), The ultrastructural organization of the columnar absorbing cells of the mouse jejunum. Monograph Aktiebolaget Godvil, Stockholm.

31. Ito, S. (1969), Fed. Proc. 28, 12-25.

32. Forstner, G. G. (1969), Am. J. Med. Sci. 258, 172-180.

33. Ito, S. (1965), J. Cell. Biol. 27, 475-490.

34. Alpers, D. H. \& Kinzie, J. L (1973), Gastroenterology 64, 471-496.

35. Mukherjee, T. M. \& Staehelin, L. A. (1971), J. Cell Sci. 8, 573-599.

36. Dahlqvist, A. \& Borgström, B. (1961), Biochem. J. 81, 411-418.

37. Miller, D. \& Crane, R. K. (1961), Biochim. Biophys. Acta 52, 293-298.

38. Oda, T. \& Seki, S. (1965), J. Electron. Micr. 14, 210-217.

39. Oda, T. \& Seki, S. (1966), In: Electron Microscopy, 6 th International Congress for Electron Microscopy vol. II, 387-388, Maruzen, Tokyo.

40. Johnson, C. F. (1967), Science 155, 1670-1672.

41. Nishi, Y., Yoshida, T. O. \& Takesue, Y. (1968), J. Molec. Biol. 37, 441-444.

42. Benson, R. L., Sacktor, B. \& Greenawalt, J. W. (1971), J. Cell. Biol. 48, 711-716.

43. Forstner, G. G. (1971), Biochem. J. 121, 781-789.

44. Maroux, S., Louvard, D. \& Baratti, J. (1973), Biochim. Biophys. Acta 321, 282-295.

45. Maroux, S., Louvard, D. \& Desnuelle, P. (1975), Proceedings of the Tenth FEBS Meeting, 55-69.

46. Maroux, S. \& Louvard, D. (1976), Biochim. Biophys. Acta 419, 189-195.

47. Ugolev, A. M. (1960), Nature (London) 188, 588-589.

48. Fogel, M. R. \& Gray, G. M. (1973), J. Appl. Physiol. 35, 263-267.

49. Hubel, K. A. \& Parsons, D. S. (1971), Am. J. Physiol. 221, $1827-1831$

50. Ugolev, A. M. (1972), Gut 13, 735-747.

51. Adlung, J. (1969), Z. Gastroenterologie 4, 304-313

52. Böhmer, R. \& Rommel, K. (1970), Klin. Wochenschr. 48, 1226-1228.

53. Crane, R. K. (1968), In: Handbook of Physiology, Section 6, Alimentary Canal. Vol. V, Intestinal Absorption. (Code, C. F., ed.) 2535-2542, American Physiological Society, Washington D.C.

54. Eichholz, A. (1968), Biochim. Biophys. Acta 163, 101-107.
55. Gitzelmann, R., Bachi, T. H., Binz, H., Lindenmann, J. \& Semenza, G. (1970), Biochim. Biophys. Acta 196, 20-28.

56. Dahlqvist, A. \& Nordström, C. (1966), Biochim. Biophys. Acta 113, 624-626.

57. Nordström, C. \& Dahlqvist, A. (1971), Biochim. Biophys. Acta 242, 209-225.

58. Das, B. C. \& Gray, G. M. (1970), Clin. Res. 18, 378.

59. James, W. P. T., Alpers, D. H., Gerber, J. E. \& Isselbacher, K. (1971), Biochim. Biophys. Acta 230, 194-203.

60. Grand, R. J., Chong, D. A. \& Isselbacher, K. J. (1972), Biochim. Biophys. Acta 261, 341-352.

61. Dahlqvist, A. \& Brun, A. (1962), J. Histochem. Cytochem 10, 294-302.

62. Auricchio, S., Semenza, G. \& Rubino, A. (1965), Biochim. Biophys. Acta 96, 498-507.

63. Dahlqvist, A. (1970), In: Biochemische und klinische Aspekte der Zuckerabsorption, (Rommel, K. \& Clodi, P. H. ed.) 1-13, Schattauer Verlag Stuttgart-New York.

64. Dahlqvist, A., Auricchio, S., Semenża, G. \& Prader, A. (1963), J. Clin. Invest. 42, 556-562.

65. Semenza, G. (1968), In: Handbook of Physiology, Section 6, Alimentary Canal. Vol. V, Intestinal Absorption. (Code, C. F., ed.) 2543-2566, American Physiological Society, Washington D.C.

66. Conklin, K. A., Yamashiro, K. M. \& Gray, G. M. (1975), J. Biol. Chem. 250, 5735-5741.

67. Gray, G. M. (1971), Ann. Rev. Med. 391-404.

68. Dubs, R., Steinmann, B. \& Gitzelmann, R. (1973), Helv. Paediat. Acta 28, 187-198.

69. Dubs, R., Gitzelmann, R., Steinmann, B. \& Lindenmann, J. (1975), Helv. Paediat. Acta 30, 89-102.

70. Gray, G. M., Conklin, K. A. \& Townley, R. R. W. (1976), N. Engl. J. Med. 294, 750-753.

71. Preiser, H., Menard, D., Crane, R. K. \& Cerda, J. J. (1974), Biochim. Biophys. Acta 363, 279-282.

72. Dahlqvist, A. \& Asp, N. G. (1975), Biochem. Soc. Trans. 3, 227-232.

73. Lojda, Z., Havránková, E. \& Slabý, J. (1974), Histochemistry 42, 271-286.

74. Sato, M. \& Yamashina, I. (1975), Biochim. Biophys. Acta $397,179-187$.

75. Gray, G. M., Santiago, N. A., Coiver, E. H. \& Genel, M. (1969), J. Clin. Invest. 48, 729-735.

76. Lorenz-Meyer, H., Blum, A. L., Haemmerli, H. P. \& Semenza, G. (1972), Europ. J. Clin. Invest. 2, 326-331:

77. Parsons, D. S. (1972), In: Transport across the intestine. (Burland, W. L. \& P. D. Samuel, eds.) 253-278, Churchill Livingstone, Edinburgh and London.

78. Rosenberg, T. (1948), Acta Chem. Scand. 2, 14-33.

79. Kedem, O. (1961), In: Membrane Transport and Metabolism, (Kleinzeller, A. \& Kotyk, A., eds.) 87, Czechoslovak. Academy of Science, Prague.

80. Danielli, J. F. \& Davson, H. (1935), J. Cell. Comp. Physiol. $5,495-508$.

81. Osterhout, W. J. V., Kamerling, S. E. \& Stanley, W. M. (1934), J. Gen. Physiol. 17, 445-467.

82. Csaky, T. Z. (1963), Fed. Proc. 22, 3-7.

83. Csaky, T. Z. (1963), Biochim. Biophys. Acta 74, 160-162.

84. Crane, R. K. (1965), Fed. Proc. 24, 1000-1005.

85. Kimmich, G. A. (1973), Biochim. Biophys. Acta 300 , 31-78.

86. Olsen, W. A. \& Ingelfinger, F. J. (1968), J. Clin. Invest. 47, 1133-1142.

87. Saltzman, D. A., Rector, F. C. Jr. \& Fordtran, J. S. (1972), J. Clin. Invest. 51, 876-885.

88. Murer, H. \& Hopfer, U. (1974), Proc. Nat. Acad. Sci. 71, 484-488 (1974).

89. Honegger, P. \& Semenza, G. (1973), Biochim. Biophys. Acta 318, 390-410 (1973).

90. Honegger, P. \& Gershon, E. (1974), Biochim. Biophys. Acta 352, 127-134.

91. Debnam, E. S. \& Levin, R. J. (1976), Gut 17, 92-99.

92. Cook, G. C. (1969), Clin. Sci. 37, 675-687.

93. Dencker, H., Lunderqvist, A., Meeuwisse, G., Norryd, C. \& Tranberg, K. G. (1972), Scand. J. Gastroent. 7, 701-705.

94. Ginsburg, V. \& Hers, H. G. (1960), Biochim. Biophys. Acta 38, 427:-434. 
95. Sigrist-Nelson, K. \& Hopfer, U. (1974), Biochim. Biophys. Acta 367, 247-254 (1974).

96. Guy, M. J. \& Deren, J. J. (1971), Am. J. Physiol. 221, $1051-1056$.

97. Gracey, M., Burke, V. \& Oshin, A. (1972), Biochim. Biophys. Acta 266, 397-406.

98. Miller, D. \& Crane, R. K. (1961), Biochim. Biophys. Acta $52,281-293$.

99. Mc Dougal, D. B. Jr., Little, K. D. \& Crane, R. K. (1960), Biochim. Biophys. Acta 45, 483-489.

100. Ramaswamy, K., Malathi, P., Caspary, W. F. \& Crane, R. K. (1974), Biochim. Biophys. Acta 345, 39-48 (1974).

101. Ramaswamy, K., Malathi, P. \& Crane, R. K. (1976), Biophys. Res. Comm. 68, 162-168.

102. Storelli, C., Vögeli, H. \& Semenza, G. (1972), FEBS Lett. 24, 287-292.

103. Crane, R. K. (1967), Symposia of the International Society for Cell Biology Vol. 5, (Warren, K. B., ed.) 71-103, Academic Press, New York.
104. Mc Michael, H. B., Webb, J. \& Dawson, A. M. (1967), Clin. Sci. 33, 135-145.

105. Mc Michael, H. B. (1972), Acta Hepatogastroenterol. 19, $281-290$.

106. Dahlqvist, A. \& Thomson, D. L. (1963), J. Physiol. 167, 193-209.

107. Murer, H., Hopfer, U., Kinne-Saffran, E. \& Kinne, R. (1974), Biochim. Biophys. Acta 345, 170-179.

108. Kimmich, G. A. \& Randles, J. (1975), J. Membrane Biol. $23,57-76$.

109. Bronk, J. R. \& Ingham, P. A. (1976), J. Physiol. (London) 255, 481-495.

110. Munck, B. G. (1972), In: Transport across the intestine, (Burland, W. L. \& Samuel, P. D. eds.) 169-185, Churchill Livingstone, Edinburgh and London.

111. Boyd, C. A. R., Cheesman, C. I. \& Parsons, D. S. (1975), Nature 256, 747-749.

112. Casley-Smith, J. R., O'Donoghue, P. J. \& Crocker, K. W. J. (1975), Microvasc. Res. 9, 78-100.

PD Dr. R. Böhmer

1. Med. Abt., Marienkrankenhaus Alfredstr. 9

2000 Hamburg 76 
